\title{
Teste de condutividade elétrica na avaliação do potencial fisiológico de sementes de berinjela
}

\author{
Electrical conductivity test in evaluating the physiological potential of eggplant seeds
}

\author{
Charline Zaratin Alves ${ }^{\mathrm{I}}$ Amanda Regina GodoyII Ana Carina da Silva Candido ${ }^{\mathrm{II}}$ \\ Naiane Cristina de Oliveira ${ }^{\mathrm{II}}$
}

\section{RESUMO}

A qualidade fisiológica é um dos principais objetos de estudos envolvendo sementes, pois estas podem sofrer uma série de mudanças degenerativas de diversas naturezas que culminam com a redução de seu vigor. Para suprir as deficiências do teste de germinação na caracterização de lotes, foram desenvolvidos testes de vigor, que estão muito bem caracterizados para as grandes culturas, mas recém aplicados para as sementes de olerícolas. Sendo assim, o presente trabalho teve como objetivo avaliar a utilização do teste de condutividade elétrica na avaliação do potencial fisiológico de sementes de berinjela. Quatro lotes de sementes de berinjela, cultivar 'Preta Comprida', foram submetidos a testes de germinação e vigor (primeira contagem da germinação, emergência das plântulas, índice de velocidade de emergência e envelhecimento acelerado). Para o teste de condutividade elétrica, foram estudadas variações no volume de água (50 e $75 \mathrm{~mL}$ ), temperatura (25 e $\left.30^{\circ} \mathrm{C}\right)$, número de sementes (25 e 50) e tempo de embebição (1, 2, 4, 6, 12, 18 e 24 horas). O teste de condutividade elétrica foi eficiente para a avaliação do vigor de sementes de berinjela, com o tempo de embebição podendo ser reduzido para quatro horas, porém a utilização de 50 sementes não permitiu diferenciar os lotes. O volume de $25 \mathrm{~mL}$ em temperatura de $30^{\circ} \mathrm{C}$ foi a condição mais favorável para a ordenação consistente dos lotes quanto ao vigor, de forma que a condição mais adequada para o teste de condutividade elétrica em sementes de berinjela é a utilização de 25 sementes em $50 \mathrm{~mL}$ de água por quatro horas a $30^{\circ} \mathrm{C}$.

Palavras-chave: Solanum melongena, vigor, lixiviação.

\section{ABSTRACT}

The physiological quality is one of the main objects of studies involving seeds, as they may suffer a series of degenerative changes of various types which lead to reduction of its vigor. To compensate the deficiencies of the germination test in the characterization of lots, vigor tests have been developed, which are already well characterized for the main crops, but recently applied to vegetables seeds. So, this study aimed to evaluate the use of electrical conductivity in the physiological potential of eggplant seeds. Four seed lots of eggplant cultivar 'Preta Comprida', were tested for germination, first count germination, seedling emergence, speed of emergence and accelerated aging. For the electrical conductivity were studied variations in the volume of water $(50$ and $75 \mathrm{~mL})$, temperature $\left(25\right.$ and $\left.30^{\circ} \mathrm{C}\right)$, number of seeds (25 and 50) and imbibed $(1,2,4,6,12,18$ and 24 hours). The electrical conductivity test was efficient for the eggplant seeds, and the soaking time can be reduced to four hours, but using 50 seeds failed to differentiate between batches. The volume of $25 \mathrm{~mL}$ and $30^{\circ} \mathrm{C}$ was the most favorable condition for the consistent ordering of the lots on the force. The best conditions for the electrical conductivity in eggplant seed is the use of 25 seeds in $50 \mathrm{~mL}$ of water for four hours at $30^{\circ} \mathrm{C}$.

Key words: Solanum melongena, vigor, leakage.

\section{INTRODUÇÃO}

A berinjela é uma solanácea que pode ser cultivada o ano inteiro, contudo, um dos principais problemas enfrentados na sua produção refere-se à dificuldade de estabelecimento adequado das plantas no campo, uma vez que a porcentagem e a uniformidade de emergência podem ter forte impacto sobre a produtividade e a qualidade final das mudas para o

'Departamento de Agronomia, Universidade Federal de Mato Grosso do Sul (UFMS), 79560-000, Chapadão do Sul, MS, Brasil. Email: charline.alves@ufms.br. Autor para correspondência.

"Departamento de Agronomia, UFMS, Chapadão do Sul, MS, Brasil. 
transplantio. As falhas na germinação e estande reduzido de plantas frequentemente têm sido atribuídos à baixa qualidade do lote de sementes utilizado para a implantação da cultura, uma vez que a maturação das sementes e frutos de berinjela é desuniforme, o que, consequentemente levaria à desuniformidade de germinação das sementes (TRIGO \& TRIGO, 1999).

$\mathrm{Na}$ tentativa de elucidar esse fato, somente o teste de germinação, na maioria das vezes, não é suficiente para detectar diferenças no potencial fisiológico das sementes, sendo que a utilização de testes de vigor se torna uma ferramenta importante nos laboratórios de análise de sementes, destacando-se o teste de condutividade elétrica. Esse teste baseia-se no princípio de que, com o processo de deterioração, ocorre aumento na lixiviação dos constituintes celulares das sementes embebidas em água, devido à perda da integridade dos sistemas de membranas celulares (HEPBURN et al., 1984).

Um dos fatores que influencia na avaliação do teste de condutividade elétrica é a temperatura utilizada para a embebição das sementes, pois esta afeta diretamente a velocidade de absorção de água pela semente e a liberação de eletrólitos do interior das células para o meio externo (MURPHY \& NOLAND, 1982). Em sementes pequenas, como as das hortaliças, a lixiviação máxima pode ocorrer num período inferior a duas horas, como em pimenta (VIDIGAL et al., 2008), enquanto que em sementes maiores, como as de soja, têm sido observados aumentos da lixiviação em até 16 horas após o início da embebição (DIAS \& MARCOS FILHO, 1996).

Para estimar o vigor de sementes de hortaliças, as pesquisas têm indicado a redução do período para a leitura da condutividade elétrica, a exemplo das sementes de pimentão, uma vez que OLIVEIRA \& NOVEMBRE (2005) verificaram que a leitura da condutividade elétrica da solução de embebição pode ser realizada em seis horas. Em sementes de abobrinha, DUTRA \& VIEIRA (2006) observaram que esse teste pode ser avaliado após oito horas de embebição, enquanto o tempo de embebição para sementes de rúcula, segundo ALVES \& SÁ (2009) pode ser reduzido para quatro horas. No entanto, para sementes de cebola, RODO (2002) e DIAS et al. (2006) constataram que esse teste foi pouco sensível na separação dos lotes de alto e baixo vigor.

Assim, o trabalho teve como objetivo estudar a metodologia do teste de condutividade elétrica para avaliação do potencial fisiológico de sementes de berinjela.

\section{MATERIAL E MÉTODOS}

O trabalho foi conduzido no Laboratório de Tecnologia de Sementes da Universidade Federal de Mato Grosso do Sul, Campus de Chapadão do Sul, utilizando-se quatro lotes de sementes de berinjela, cultivar Preta Comprida, não tratados quimicamente.

O teor de água foi determinado, sendo também realizados os testes de germinação, primeira contagem de germinação, emergência, envelhecimento acelerado e variações na condução do teste de condutividade elétrica. A determinação do teor de água foi realizada através do método da estufa a $105 \pm 3^{\circ} \mathrm{C}$ durante 24 horas, utilizando-se duas subamostras com aproximadamente $2 \mathrm{~g}$ para cada lote (BRASIL, 2009). Para o teste de germinação, foram utilizadas quatro repetições de 50 sementes para cada lote, distribuídas uniformemente sobre duas folhas de papel germitest dentro de caixas plásticas tipo gerbox, umedecidas com água destilada na proporção de 2,5 vezes o peso do papel seco e colocadas para germinar a $20-30^{\circ} \mathrm{C}, \operatorname{com} 8$ horas de escuro e 16 de luz, com contagens realizadas aos sete e 14 dias após a semeadura (BRASIL, 2009). A primeira contagem de germinação foi realizada em conjunto com o teste de germinação, determinando-se a porcentagem de plântulas normais no sétimo dia após a sua instalação (BRASIL, 2009). O índice de velocidade de germinação foi calculado através da soma do número de sementes germinadas a cada dia, dividido pelo respectivo número de dias transcorridos a partir da semeadura (MAGUIRE, 1962).

Para a emergência das plântulas, foram utilizadas bandejas de isopor com 128 células individuais, contendo substrato comercial Plantmax ${ }^{\circledR}$, as quais foram mantidas em casa de vegetação com controle de temperatura $\left(25^{\circ} \mathrm{C}\right)$, sendo realizadas três regas diárias, em quatro repetições de 50 sementes por lote, colocando-se uma semente por célula. A avaliação da emergência das plântulas foi efetuada aos quatorze dias após a semeadura, quando se verificou a estabilidade da emergência mediante a contagem de plântulas normais emergidas. $O$ teste de envelhecimento acelerado foi realizado com 200 sementes para cada lote, sendo distribuídas uniformemente sobre tela acoplada à caixa gerbox com $40 \mathrm{~mL}$ de água destilada. As caixas foram tampadas e mantidas em câmara B.O.D. (Biochemical Oxygen Demand) a $41^{\circ} \mathrm{C}$ por $72 \mathrm{~h}$ e, decorrido este período, quatro repetições de 50 sementes foram submetidas ao teste de germinação, conforme metodologia descrita anteriormente, com os resultados expressos em 
porcentagem de plântulas normais obtidas no sétimo dia após a semeadura.

Para o teste de condutividade elétrica, foram estudadas variações no número de sementes (25 e 50), volume de água destilada $(50$ e $75 \mathrm{~mL})$, temperatura $(25$ e $\left.30^{\circ} \mathrm{C}\right)$ e período de embebição $(1,2,4,6,12,18$ e 24 horas). Quatro subamostras de sementes fisicamente puras para cada lote foram pesadas em balança de precisão de $0,0001 \mathrm{~g}$ e colocadas para embeber em copos plásticos contendo água destilada, sendo posteriormente mantidos em germinador durante cada período de embebição, dentro de cada temperatura estudada. As leituras da condutividade elétrica foram realizadas em condutivímetro Digimed DM-31 e os valores médios obtidos para cada lote expressos em $\mu \mathrm{S} \mathrm{cm} \mathrm{cm}^{-1} \mathrm{~g}^{-1}$ de semente.

O delineamento experimental foi o inteiramente casualizado, com quatro repetições por lote, sendo que a comparação das médias foi realizada pelo teste de Tukey, em nível de 5\% de probabilidade.

\section{RESULTADOS E DISCUSSÃO}

O teor de água inicial das sementes $(6,0 \%)$ não variou entre os lotes (Tabela 1), fato que é importante na execução dos testes, considerando-se que a uniformização do teor de água das sementes é imprescindível para a padronização das avaliações e obtenção de resultados consistentes (MARCOS FILHO et al., 1987; LOEFFLER et al., 1988). Os dados do teor de água não foram analisados estatisticamente, servindo apenas para a caracterização inicial dos lotes de sementes de berinjela.

Pelos resultados do teste de germinação, observa-se que o lote 1 foi estatisticamente superior aos demais (Tabela 1); também os testes de primeira contagem de germinação e de envelhecimento acelerado destacaram o lote 1 como o mais vigoroso, permitindo também identificar o lote 4 com um vigor intermediário e os lotes 2 e 3 com menor vigor. Os testes de emergência de plântulas e índice de velocidade de emergência conseguiram ordenar todos os lotes com relação ao vigor, destacando o lote 1 como o mais vigoroso e, na sequência, os lotes 4,3 e 2, todos diferindo estatisticamente entre si, sendo que o lote 2 foi considerado o de menor vigor.

Assim, de acordo com a caracterização inicial dos lotes de sementes de berinjela, constatou-se que, com exceção do teste de germinação, os demais testes empregados tiveram a mesma ordenação em relação ao vigor dos lotes, sendo o lote 1 mais vigoroso e os lotes 2 e 3 menos vigorosos. Os testes de emergência e índice de velocidade de emergência foram mais sensíveis às diferenças de qualidade entre os lotes, estratificandoos em quatro níveis de potencial fisiológico, ou seja, alto vigor para o lote 1, vigor intermediário para os lotes 3 e 4 e menor vigor para o lote 2 .

O teste de condutividade elétrica conduzido a $25^{\circ} \mathrm{C}$, independentemente da quantidade de sementes ( 25 e 50$)$ e de água $(50$ e $75 \mathrm{~mL}$ ) (Tabelas 2 e 3 ) não foi eficiente na separação dos lotes 1 e 4 em diferentes níveis de qualidade fisiológica para sementes de berinjela.

Na condição do teste, com a utilização de 25 sementes a $30^{\circ} \mathrm{C}$, recipiente contendo $50 \mathrm{~mL}$ de água destilada e duas horas de embebição, os lotes 2 e 3 destacaram-se dos demais, com valores de condutividade superiores aos dos outros lotes, com desempenho inferior do lote devido ao maior conteúdo de exsudatos lixiviados pelas sementes, demonstrando maior grau de deterioração de suas membranas (Tabela 4) e, em trabalho com sementes de pimentão, OLIVEIRA \& NOVEMBRE (2005) também identificaram o lote de maior vigor com uma hora de imersão das sementes a $30^{\circ} \mathrm{C}$.

Tabela 1 - Caracterização da qualidade inicial de sementes de berinjela, cv. Preta Comprida, pela umidade, germinação, primeira contagem de germinação, envelhecimento acelerado, emergência de plântulas e índice de velocidade de emergência.

\begin{tabular}{|c|c|c|c|c|c|c|}
\hline Lotes & Umidade & Germinação & Primeira contagem & Envelhecimento acelerado & Emergência de plântulas & IVE \\
\hline 1 & 6,0 & 99 a & $92 \mathrm{a}$ & $87 \mathrm{a}$ & $86 \mathrm{a}$ & $14,0 \mathrm{a}$ \\
\hline 2 & 6,0 & $65 \mathrm{~b}$ & $41 \mathrm{c}$ & $20 \mathrm{c}$ & $44 \mathrm{~d}$ & $4,0 \mathrm{~d}$ \\
\hline 3 & 6,0 & $67 \mathrm{~b}$ & $40 \mathrm{c}$ & $22 \mathrm{c}$ & $51 \mathrm{c}$ & $6,5 \mathrm{c}$ \\
\hline 4 & 6,0 & $67 \mathrm{~b}$ & $52 \mathrm{~b}$ & $40 \mathrm{~b}$ & $63 \mathrm{~b}$ & $9,5 \mathrm{~b}$ \\
\hline CV (\%) & - & 7,22 & 6,87 & 10,29 & 11,21 & 8,88 \\
\hline
\end{tabular}

Na coluna, médias seguidas da mesma letra não diferem entre si, pelo teste de Tukey, a 5\% de probabilidade.

IVE = índice de velocidade de emergência. 
Tabela 2 - Dados médios de condutividade elétrica $\left(\mu \mathrm{S} \mathrm{cm} \mathrm{g}^{-1}\right)$ de sementes de berinjela, cv. Preta Comprida, nas combinações de 25 sementes $50 \mathrm{~mL}^{-1}$ e 25 sementes $75 \mathrm{~mL}^{-1}$ de água, a $25^{\circ} \mathrm{C}$, em diferentes períodos de embebição.

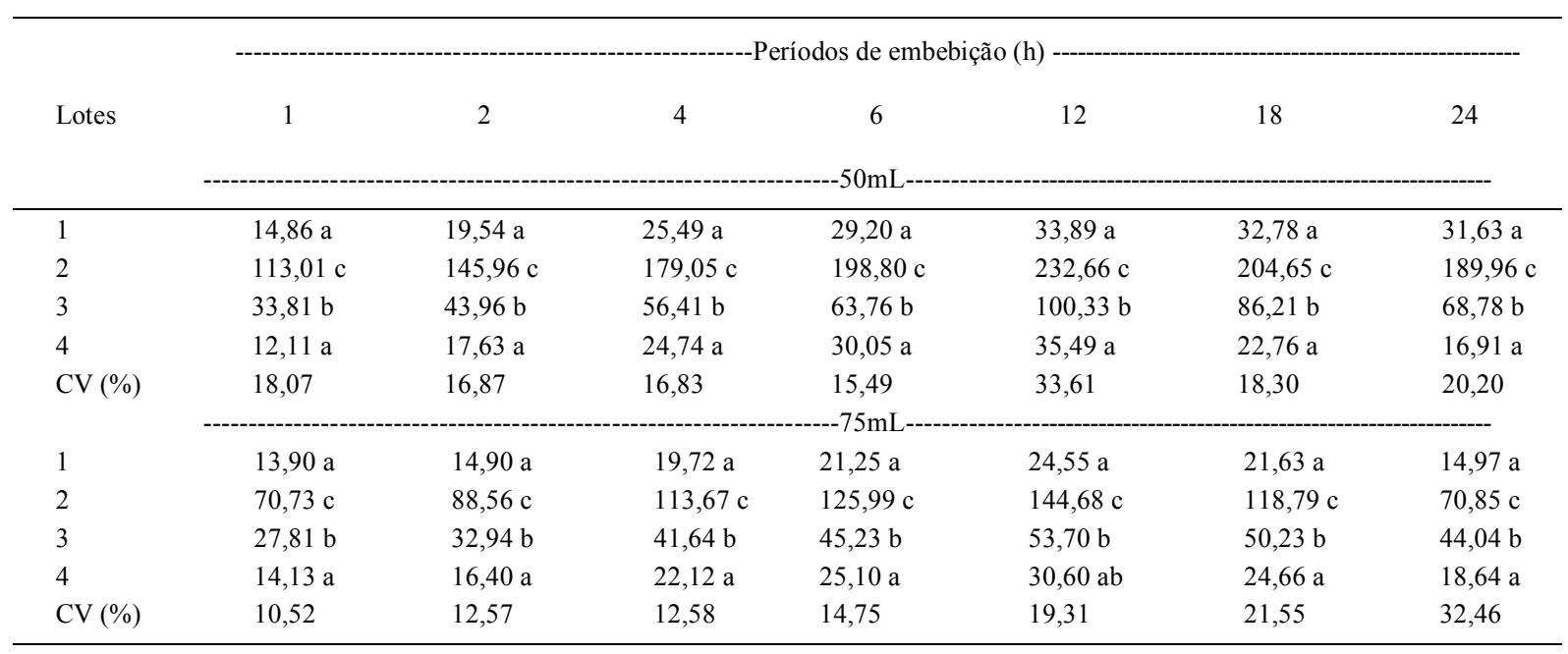

Na coluna, médias seguidas da mesma letra não diferem entre si, pelo teste de Tukey, a 5\% de probabilidade.

A partir de quatro horas de embebição, percebeu-se maior diferenciação dos lotes quanto ao nível de vigor das sementes de berinjela, mas vale ressaltar a similaridade de ordenação dos lotes, tanto no período de quatro como de dezoito horas de embebição, indicando que a condutividade manteve a mesma tendência durante estes períodos, permitindo a realização do teste em menor tempo e, consequentemente, a obtenção mais rápida dos resultados.

Na pesquisa realizada por DUTRA \& VIEIRA (2006) com sementes de abobrinha, resultados similares foram verificados, em que a classificação de lotes similar foi obtida para oito e 24 horas de embebição. Outros autores também reduziram o tempo de embebição em relação às 24 horas indicadas (OLIVEIRA \& NOVEMBRE, 2005).

Ainda na tabela 4 observou-se que, para o volume de $75 \mathrm{~mL}$ de água, não houve similaridade na ordenação dos lotes em comparação com as avaliações iniciais de qualidade das sementes, ou seja, este volume não permitiu a diferenciação entre os lotes 1 e 4 .

Tabela 3 - Dados médios de condutividade elétrica $\left(\mu \mathrm{S} \mathrm{cm} \mathrm{g}^{-1}\right)$ de sementes de berinjela, cv. Preta Comprida, nas combinações de 50 sementes $50 \mathrm{~mL}^{-1}$ e 50 sementes $75 \mathrm{~mL}^{-1}$ de água, a $25^{\circ} \mathrm{C}$, em diferente períodos de embebição.

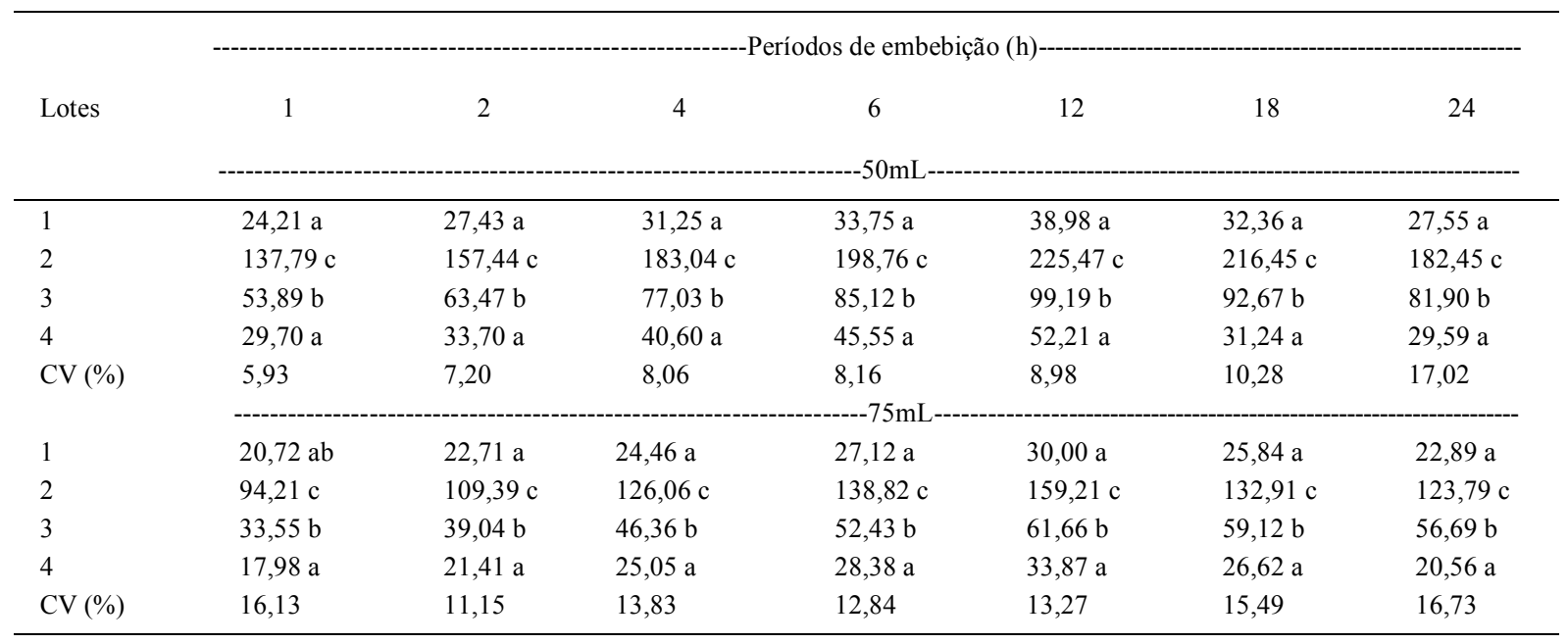

Na coluna, médias seguidas da mesma letra não diferem entre si, pelo teste de Tukey, a 5\% de probabilidade.

Ciência Rural, v.42, n.6, jun, 2012. 
Tabela 4 - Dados médios de condutividade elétrica $\left(\mu \mathrm{S} \mathrm{cm} \mathrm{cm}^{-1} \mathrm{~g}^{-1}\right)$ de sementes de berinjela, cv. Preta Comprida, nas combinações de 25 sementes $50 \mathrm{~mL}^{-1}$ e 25 sementes $75 \mathrm{~mL}^{-1}$ de água, a $30^{\circ} \mathrm{C}$, em diferentes períodos de embebição.

\begin{tabular}{|c|c|c|c|c|c|c|c|}
\hline \multirow{2}{*}{ Lotes } & \multicolumn{7}{|c|}{ Períodos de embebição (h)- } \\
\hline & 1 & 2 & 4 & 6 & 12 & 18 & 24 \\
\hline 1 & $29,29 \mathrm{a}$ & $33,83 \mathrm{a}$ & $36,62 \mathrm{a}$ & $42,91 \mathrm{a}$ & $39,61 \mathrm{a}$ & $34,58 \mathrm{a}$ & $29,26 \mathrm{a}$ \\
\hline 2 & $221,85 \mathrm{~b}$ & $217,38 \mathrm{c}$ & $250,73 \mathrm{~d}$ & $284,99 \mathrm{~d}$ & $273,61 \mathrm{~d}$ & $220,47 \mathrm{~d}$ & $125,32 \mathrm{c}$ \\
\hline 3 & $66,27 \mathrm{a}$ & $79,15 \mathrm{~b}$ & $98,05 \mathrm{c}$ & $105,43 \mathrm{c}$ & $114,84 \mathrm{c}$ & $104,22 \mathrm{c}$ & $98,16 \mathrm{bc}$ \\
\hline 4 & $41,82 \mathrm{a}$ & $48,59 \mathrm{ab}$ & $68,38 \mathrm{~b}$ & $72,68 \mathrm{~b}$ & $78,30 \mathrm{~b}$ & $66,33 \mathrm{~b}$ & $51,54 \mathrm{ab}$ \\
\hline CV $(\%)$ & 20,03 & 19,28 & 15,61 & 12,16 & 12,89 & 15,44 & 30,06 \\
\hline 1 & $18,07 \mathrm{a}$ & $22,15 \mathrm{a}$ & $25,73 \mathrm{a}$ & $28,29 \mathrm{a}$ & 29,56 a & $24,43 \mathrm{a}$ & $20,10 \mathrm{a}$ \\
\hline 2 & $138,45 \mathrm{~b}$ & $161,21 \mathrm{~b}$ & $191,41 \mathrm{c}$ & $213,36 \mathrm{c}$ & $220,88 \mathrm{c}$ & $162,48 \mathrm{c}$ & $93,86 \mathrm{~b}$ \\
\hline 3 & $46,89 \mathrm{a}$ & $57,64 \mathrm{a}$ & $73,19 \mathrm{~b}$ & $85,07 \mathrm{~b}$ & $97,29 \mathrm{~b}$ & $90,21 \mathrm{~b}$ & $82,68 \mathrm{~b}$ \\
\hline 4 & 26,93 a & $30,67 \mathrm{a}$ & $36,76 \mathrm{ab}$ & $41,23 \mathrm{ab}$ & $44,98 \mathrm{a}$ & $32,96 \mathrm{a}$ & $18,77 \mathrm{a}$ \\
\hline CV (\%) & 36,88 & 30,69 & 26,03 & 23,59 & 21,87 & 24,56 & 30,13 \\
\hline
\end{tabular}

Na coluna, médias seguidas da mesma letra não diferem entre si, pelo teste de Tukey, a 5\% de probabilidade.

De acordo com os dados da tabela 5, também se verificou que, com 50 sementes a $30^{\circ} \mathrm{C}$, nenhum dos volumes de água testados $(50$ e $75 \mathrm{~mL})$ possibilitou a diferenciação dos lotes 1 e 4, classificando-os num mesmo nível de vigor, o que não coincidiu com os resultados da avaliação inicial dos lotes de sementes de berinjela. Em outras pesquisas, os resultados foram contrários aos obtidos neste trabalho, como, por exemplo, em sementes de feijão caupi, DUTRA et al (2006) verificaram que a condição mais adequada para o teste de condutividade elétrica foi a utilização de 50 sementes a $30^{\circ} \mathrm{C}$.
Considerando a facilidade de execução, objetividade e rapidez do teste de condutividade elétrica, este é indicado como rotina num laboratório para análise de sementes de berinjela.

\section{CONCLUSÃO}

O teste de condutividade elétrica para sementes de berinjela deve ser conduzido com repetições de 25 sementes cada, utilizando-se $50 \mathrm{~mL}$ de água e período de embebição de quatro horas, a $30^{\circ} \mathrm{C}$.

Tabela 5 - Dados médios de condutividade elétrica $\left(\mu \mathrm{S} \mathrm{cm} \mathrm{cm}^{-1} \mathrm{~g}^{-1}\right)$ de sementes de berinjela, cv. Preta Comprida, nas combinações de 50 sementes $50 \mathrm{~mL}^{-1}$ e 50 sementes $75 \mathrm{~mL}^{-1}$ de água, a $30^{\circ} \mathrm{C}$ em diferentes períodos de embebição.

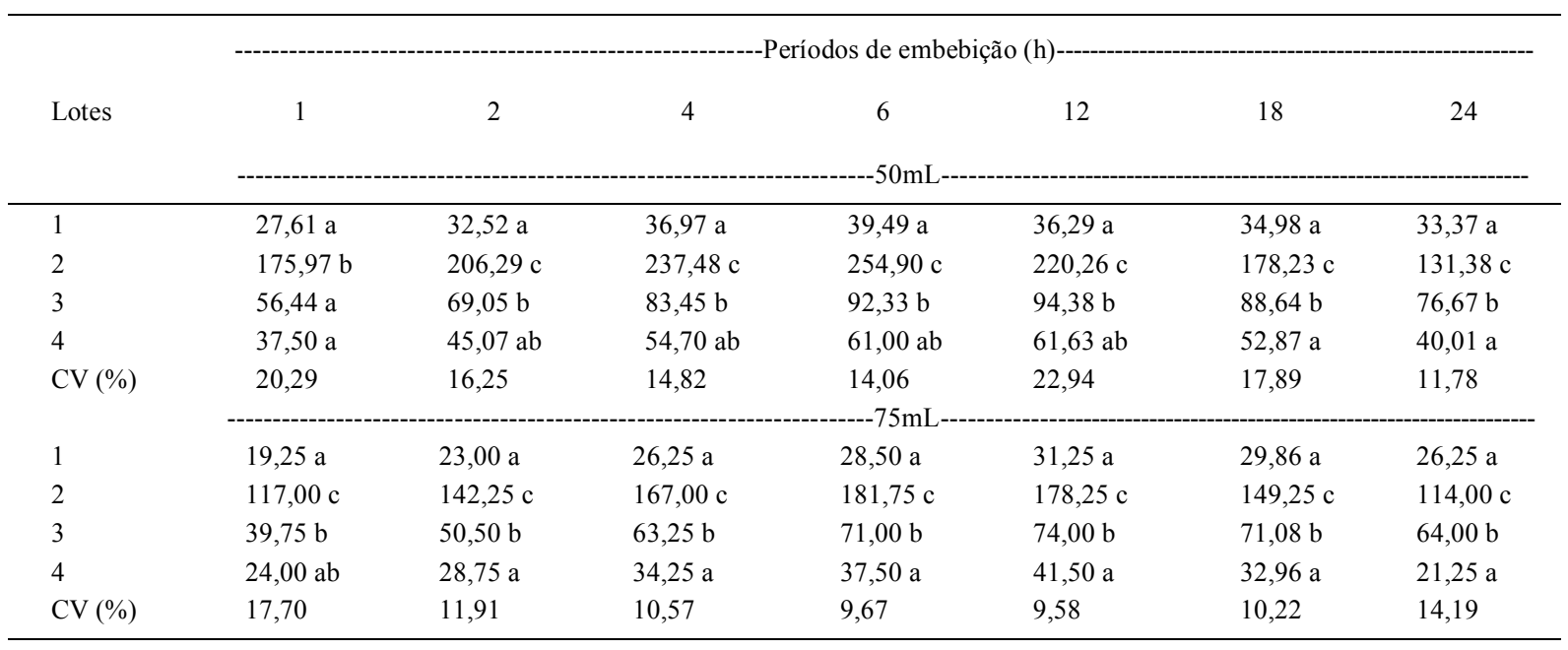

Na coluna, médias seguidas da mesma letra não diferem entre si, pelo teste de Tukey, a 5\% de probabilidade.

Ciência Rural, v.42, n.6, jun, 2012. 


\section{AGRADECIMENTOS}

À Isla Sementes, pela doação das sementes para o desenvolvimento deste trabalho.

\section{REFERÊNCIAS}

ALVES, C.Z.; SÁ, M.E. Teste de condutividade elétrica na avaliação do vigor de sementes de rúcula. Revista Brasileira de Sementes, v.31, n.1, p.203-215, 2009. Disponível em: $<$ ht t p://www.scielo.br/scielo.php?script= sci_arttext\&pid=S0101-31222009000100023\&1ng= pt\&nrm=isot>. Acesso em: 18 abr. 2011. doi: 10.1590/S010131222009000100023 .

BRASIL. Ministério da Agricultura, Pecuária e Abastecimento. Regras para análise de sementes. Secretaria de Defesa Agropecuária. Brasília: MAPA/ACS, 2009. 395p.

DIAS, D.C.F.S.; MARCOS FILHO, J. Testes de condutividade elétrica para avaliação do vigor de sementes de soja (Glycine $\max ($ L.) Merrill). Scientia Agrícola, v.53, n.1, p.31-42, 1996. Disponível em: <http://www.scielo.br/ scielo.php?pid=S0103-90161996000100005\& script $=$ sci_arttext>. Acesso em: 25 jan. 2012. doi: 10.1590/S010390161996000100005 .

DIAS, D.C.F.S. et al. Teste de condutividade elétrica para avaliação do vigor de sementes de cebola. Revista Brasileira de Sementes, v.28, n.1, p.154-162, 2006.

DUTRA, A.S.; VIEIRA, R.D. Teste de condutividade elétrica para avaliação do vigor de sementes de abobrinha. Revista Brasileira de Sementes, v.28, n.2, p.117-122, 2006. Disponível em: <http://www.scielo.br/ scielo.php?script=sci_arttext\&pid=S0101$31222006000200015 \& \operatorname{lng}=\mathrm{pt} \& \mathrm{nrm}=\mathrm{iso} \& \mathrm{t} \operatorname{lng}=\mathrm{pt}>$. Acesso em: 20 abr. 2011. doi: 10.1590/S0101-31222006000200015.

DUTRA, A.S. et al. Condutividade elétrica em sementes de feijão caupi. Revista Ciência Agronômica, v.37, n.2, p.166$170,2006$.

HEPBURN, H.A. et al. Problems associated with the routine application of electrical conductivity measurements of individual seeds in the germination testing of peas and soybeans. Seed Science and Technology, v.12, n.3, p.403-413, 1984.

LOEFFLER, T.M. et al. The bulk conductivity test as an indicator of soybean quality. Journal of Seed Technology, v.12, n.1, p.37-53, 1988.

MAGUIRE, J.D. Speed of germination-aid in selection and evaluation for seedling emergence and vigour. Crop Science, v.2, n.2, p.176-177, 1962.

MARCOS FILHO, J. et al. Avaliação da qualidade das sementes. Piracicaba: FEALQ/USP, 1987. 230p.

MURPHY, J.B.; NOLAND, T.L. Temperature effects on seed imbibition and leakage mediated by viscosity and membranes. Plant Physiology, v.69, n.2, p.428-431, 1982.

OLIVEIRA, S.R.S.; NOVEMBRE, A.D.L.C. Teste de condutividade elétrica para as sementes de pimentão. Revista Brasileira de Sementes, v.27, n.1, p.31-36, 2005. Disponível em: <http://www.scielo.br/scielo.php?script=sci_arttext\&pid= S0101-31222005000100004\&lng=pt\&nrm=iso\&tlng=pt $>$. Acesso em: 25 maio, 2011. doi: 10.1590/S010131222005000100004 .

RODO, A.B. Avaliação do potencial fisiológico de sementes de cebola e sua relação com o desempenho das plântulas em campo. 2002. 123f. Tese (Doutorado em Fitotecnia) Escola Superior de Agricultura "Luiz de Queiroz", Universidade de São Paulo, Piracicaba, SP.

TRIGO, M.F.O.O.; TRIGO, L.F.N. Efeito do condicionamento osmótico na germinação e no vigor de sementes de berinjela (Solanum melongena L.). Revista Brasileira de Sementes, v.21, n.1, p.107-113, 1999.

VIDIGAL, D.S. et al. Teste de condutividade elétrica para semente de pimenta. Revista Brasileira de Sementes, v.30, n.1, p.168-174, 2008. Disponível em <http://www.scielo.br/ s c i e lo.php ? s cript=s ci_art text\&pid=S 0101 $31222008000100021 \& \operatorname{lng}=\mathrm{pt} \& \mathrm{nrm}=\mathrm{iso} \& \mathrm{t} \operatorname{lng}=\mathrm{pt}>$. Acesso em 19 abr. 2011. doi: 10.1590/S0101-31222008000100021. 